\title{
Study of qualified cyclists movements' coordination structure in period of overcoming fatigue during differently oriented trainings
}

\author{
Kolumbet A.N.
}

Kiev National University of Technology and Design

\begin{abstract}
Purpose:

to study special aspects of pedaling structure and create diagnostic models of cyclists movements' coordination structure under fatigue in differently oriented trainings.

Material: $\quad$ in the research 18 elite sportsmen participated. Sportsmen fulfilled training programs on ergo-meter, directed on development of speed-power potentials and endurance in anaerobic and aerobic work.

Results: $\quad$ it was found that in period of fatigue overcoming dynamic shocks in applied efforts disappear and the picture of bio-dynamic components becomes smoother. With it, relative usage of efforts' horizontal components increases. In period of evident fatigue variability of movements' kinematic characteristics and integrated bio-electrical activity of the tested muscles increase; cyclists' efficiency reduces.

Conclusions: distinctions in movements' structure of cyclists in period of fatigue overcoming witness about certain tendency to transition from impulse-type pedaling to circular type. It pre-conditioned increase importance efforts' components and effectiveness of their usage.

Keywords: fatigue, cyclists, pedaling, electric myography.
\end{abstract}

\section{Introduction}

One of effective methodic technique of sportsmen movements' structure perfection is training of movements' technique in fatigue state $[4,9,22,30]$. However, in this works there is no specifying of fatigue's phase structure. Meanwhile, it is known that fatigue, resulted from tensed muscular work in sports, includes periods of surmountable (compensated) and not-surmountable (evident) fatigue $[15,18,23]$.

The existing ideas about fatigue's influence on sportsmen movements' structures were formed on the base of testing repeated loads, modeling, mainly, competition functioning. With it, dynamic of fatigue's influence on sportsmen's movements' coordination structure actually has not been studied. In such cases rather ambiguous is information about the following elements: degree of fatigue's influence; character of provoked adaptation reactions; training effect of single work and series of repeated analogous loads [19, 24].

The purpose of the present work is study of pedaling structure and creation of diagnostic models of cyclists' movements' coordination structure under fatigue in differently oriented trainings.

\section{Material and methods}

Participants: in the research 18 elite sportsmen participated (members of cycling on track combined team of Ukraine).

Organization of the research: special aspects of cyclists' movements' coordination were studied in experiment, modeling differently oriented trainings. Sportsmen fulfilled training programs (on modified ergometer "Monark"), directed at development of speedpower potentials and endurance in anaerobic and aerobic works. Speed-power trainings were the following: 12-14 accelerations, (each lasted 15 seconds) at loads $3.0-3.5 \mathrm{~kg}$ with pulse within 185-210 bpm. Anaerobic trainings were the following: 6-8 series of acceleration (4 accelerations

(c) Kolumbet A.N., 2017

doi:10.15561/20755279.2017.0204 of 60 seconds duration at load 2.0-2.5 kg and pulse within 175-190 bpm. Aerobic trainings were: work with pulse at threshold of anaerobic metabolism (to be determined individually); duration 60-120 minutes and load 2.0-2.5 $\mathrm{kg}$.

In our work we used complex method for biomechanical tests in laboratory experiment and in natural conditions of sport training. We studied dynamic of kinematic and dynamic characteristics of efforts' horizontal and vertical components, applied to right pedal. Besides, we studied special aspects of thigh quadriceps and biceps, shin and frontal tibial muscle of right leg. When analyzing electric myogram we determined: amplitude and frequency of bio-potentials, rhythm structure of absolute and relative bio-electrical activity and muscles integrated bio-electrical activity. Besides, we calculated indicators of effectiveness and efficiency of motor functioning: we determined variability of the studied movements' characteristics. Control of pedaling velocity was fulfilled with the help of electronic leader of pedaling velocity [20].

In our complex pedagogic, bio-mechanical and biological tests we followed Ukrainian legislation on health protection, Helsinki declaration 2000, directive №86/609 of European community on people’s participation in medical-biological researches.

Statistical analysis: in experimental data processing we found: mean values of indicators and their errors $(X \pm m)$, difference between average values and its confidence ( $\mathrm{t}$, p). Besides we determined dispersion magnitude - variant around average value $(\sigma, \mathrm{CV})$ and correlation between the tested indicators (r).

\section{Results}

Analysis of pedaling velocity dynamic showed periods of working in, "stable workability" and fatigue's overcoming.

In the initial period of work we observed reduction of pedaling velocity, weakening of muscles' contracting activity. Besides, we observed certain tendency to 
increase of efficiency and effectiveness of efforts (see figs. 1-4). The period of working in is also characterized by significant variability and diversity of bio-mechanical characteristics' changes, which are more expressed in trainings of anaerobic and speed-power orientation.

Then (after 28.7-35.1\% of time from the beginning of work) stabilization of pedaling velocity and indicators of cyclists' movements' structure took place. In period of "stable workability" (its duration was from 22.6 to $33.1 \%$ from total duration of trainings) we observed little variability of kinematic (from 3.6 to $8.7 \%$ ) and dynamic (from 6.8 to $13.0 \%$ ) efforts' characteristics. Besides, we noted reduction (by 6.9-8.7\%) of resulting force impulse $(p<0.05)$ and intensity of muscles' electrical activity $(p<0.05)$. Reduction of the tested indicators' variability and efficiency of motor functioning are confidently expressed only in trainings, directed at speed power potentials and endurance in anaerobic work. In work of aerobic character we noted constant change of value and sign of pedaling structure's parameters.

In final phase of training (after $57.4-62.2 \%$ of time from the beginning of work) need in sustaining of workability at pre-set level is perceived by the tested as significant difficulty. With it, (in spite of fatigue) cyclists keep the temp of pedaling still rather long time. In aerobic trainings sportsmen even increased pedaling temp to some extent.

Comparative analysis of the data in period of fatigue overcoming and in period of "stable workability" showed that integrated bio-electrical activity of the tested muscles increases (and the more work intensity is, the more increase of bio-electrical activity) (see figs. 1-4). In aerobically oriented trainings integrated bio-electrical activity of muscles in period of fatigue's overcoming increased, comparing with period of "stable workability", only by $2.5 \%$. In trainings of speed-power and anaerobic character integrated bio-electrical activity of the tested muscles increased accordingly by $18.4 \%$ and by $17.7 \%$ $(\mathrm{p}<0.01)$.

Alongside with it, it was found that increase of resulting muscles' contraction effect is determined by different correlation and degree of changes of quantitative

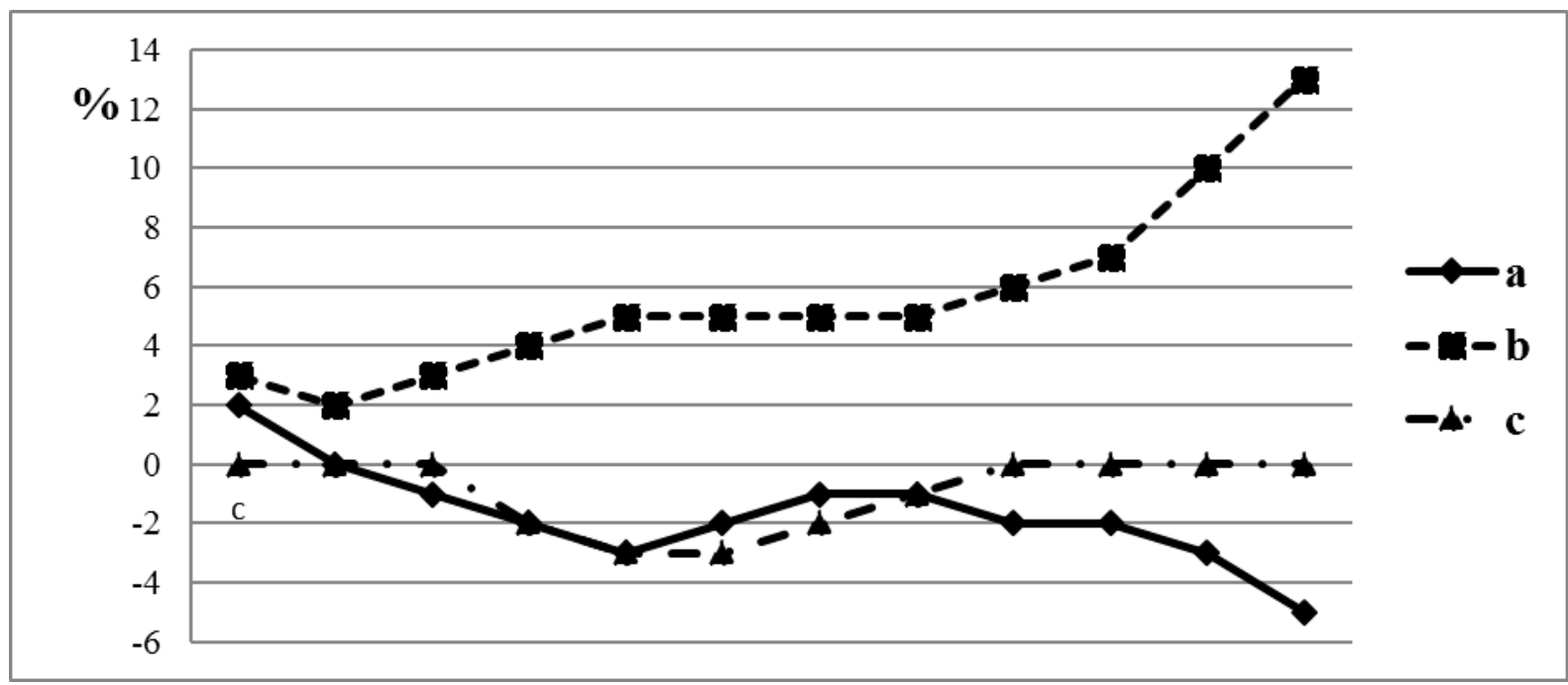

Fig. 1. Changes of pedaling velocity (\%) of qualified cyclists in speed-power (a), anaerobic (b) and aerobic (c) orientation.

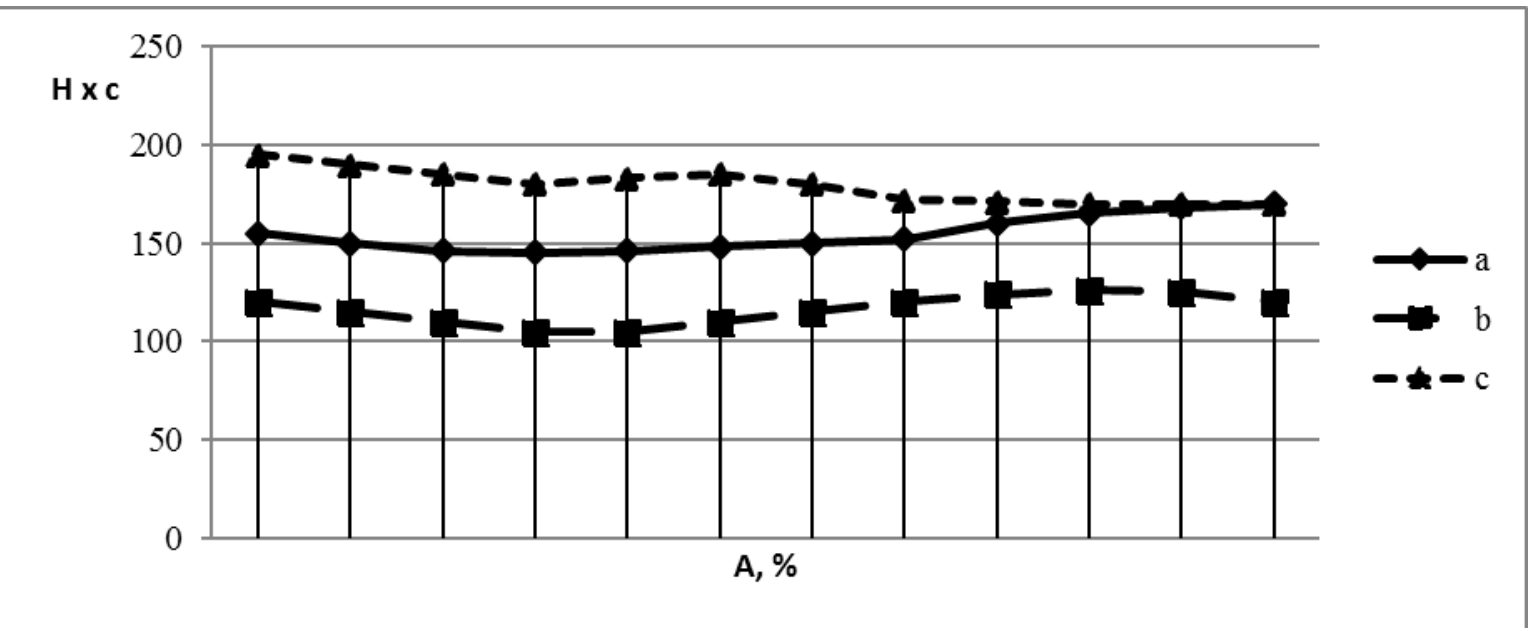

Fig. 2. Change of resulting force impulse $(H \bullet c)$ for elite cyclists' pedaling cycle in trainings of speed power (a), anaerobic (b) and aerobic (c) orientation. A - Period of training. 


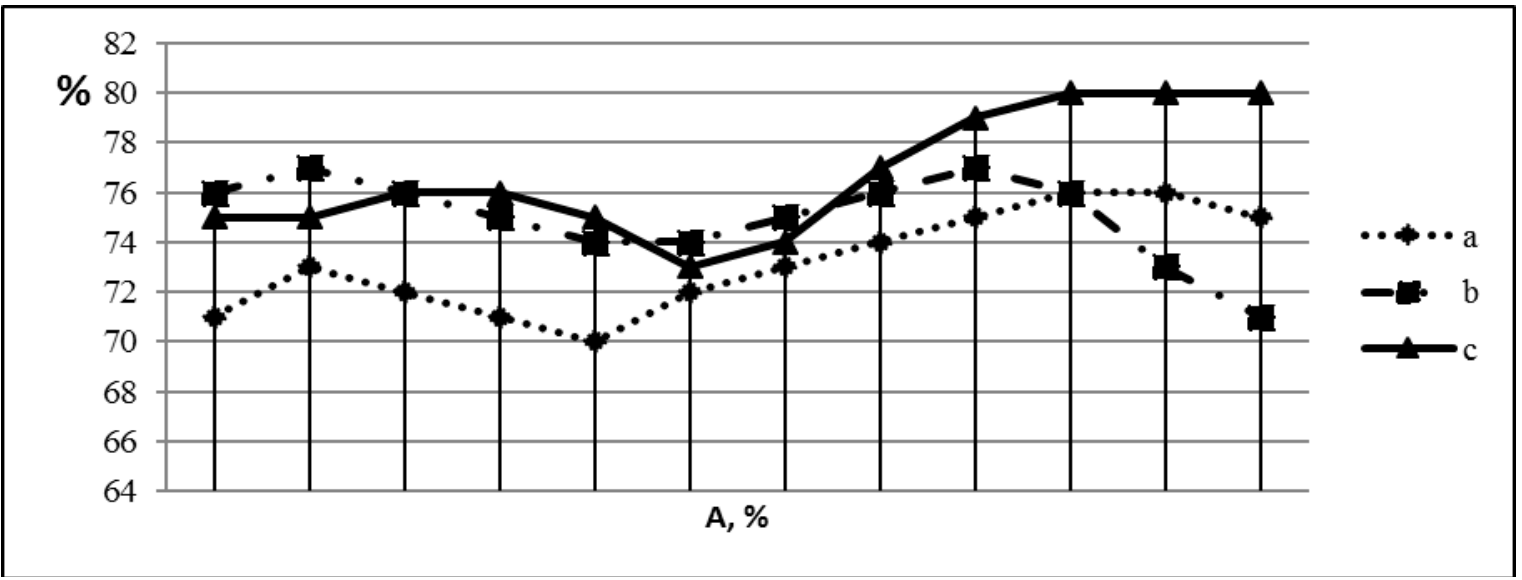

Fig. 3. Change of effectiveness of efforts (\%) in elite cyclists in trainings of speed power (a), anaerobic (b) and aerobic (c) orientation. A - Period of training.

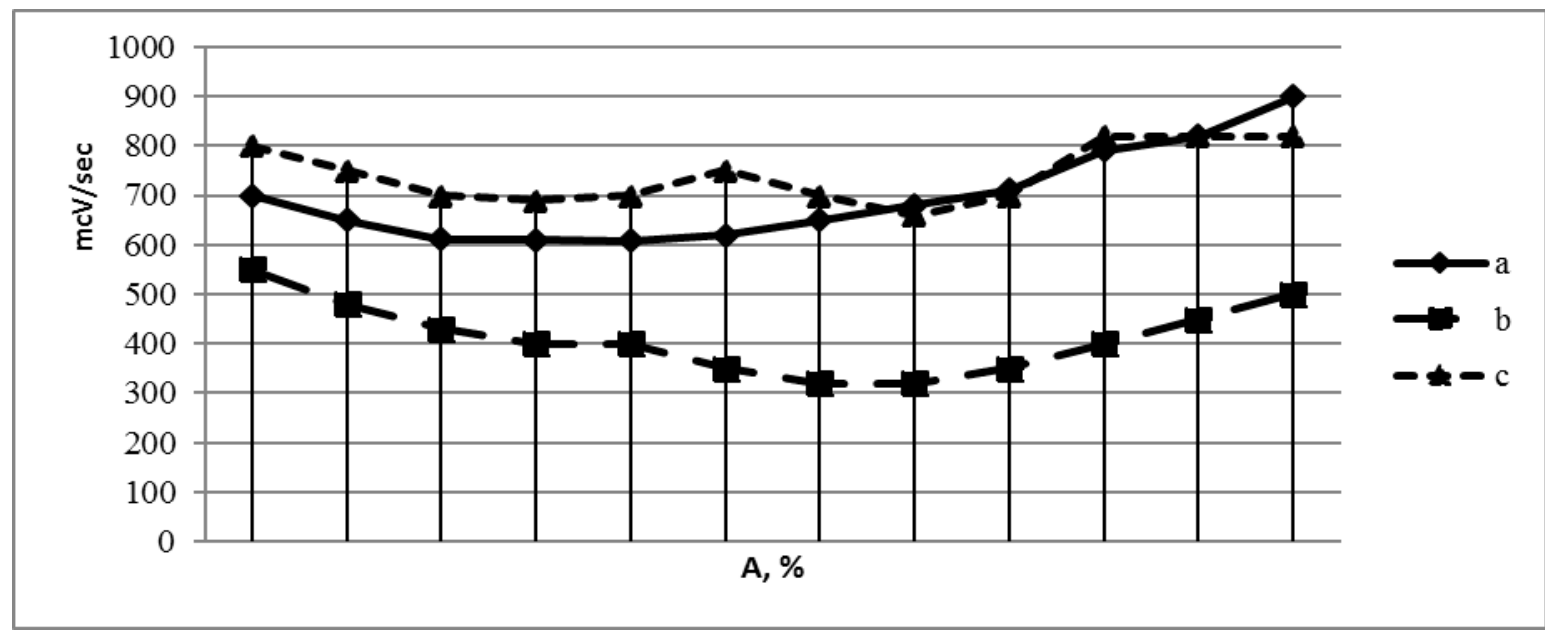

Fig. 4. Changes of integrated electrical activity of muscles $(\mathrm{mcV} / \mathrm{sec})$ of elite cyclists in trainings of speed power (a), anaerobic (b) and aerobic (c) orientation. A - Period of training.

and space characteristics of innervations structure of muscles' contracting activity (see figs. 1-4).

Analysis of correlations of muscles' bio-electrical activity characteristics permitted to mark out the factors, determining ( $\mathrm{r}$ within from 0.60 to $0.87, \mathrm{p}<0.01$ ) increase of integrated bio-electrical activity of muscles. In period of fatigue overcoming we noted increase of amplitude and reduction of bio-potentials' frequency. Rhythm structure of bio-electrical activity in most of the tested muscles (except calf muscles) remained unchanged.

Recruiting of additional motor units is not the single mechanism of sustaining the required motor effect in conditions of muscles' reduced contraction function. In aerobically oriented trainings (work with moderate intensity) gradation of muscular contraction strength was realized mainly at the account of motor-neurons' activity rhythm's change. With it, by the end of training frequency of bio-potentials' oscillations of all muscles simultaneously increased. In comparison with period of "stable workability", frequency of oscillations increased by $4.0-17.0 \%(\mathrm{p}<0.05)$ (see figs. $1-4)$.

In period of fatigue's overcoming re-distribution of activity between tested muscles takes place and internal innervations structure of movements' changes. Changes of inter-muscular activity in period of fatigue's overcoming are the most characteristic for work of moderate intensity. They are less expressed in speed-power oriented trainings [20].

Analysis of cyclists' tensor-dynamic graphs (figs. 5-7) showed that by the end of training dynamic shocks in character of applied efforts disappear. The picture of biodynamic components becomes smoother. Independent on training's orientation relative usage of efforts' horizontal components increases. Impulse of vertical efforts' force does not change significantly. These distinctions in the structure of sportsmen's movements witness about certain tendency to transition from "impulse" type of pedaling to "circular" type. It pre-conditioned increase of importance of efforts' useful components. As a result there was increase of their usage effectiveness in period of fatigue's overcoming $(r=0.76, \mathrm{p}<0.05)$.

It should also be noted that in the process of progressing and overcome fatigue it is necessary to distinguish period of irresistible (evident) fatigue. The period of evident fatigue was observed only at trainings of speed-power and anaerobic orientation. At trainings of aerobic character pedaling velocity remained practically unchanged up to the moment of "refusal to work". In this 


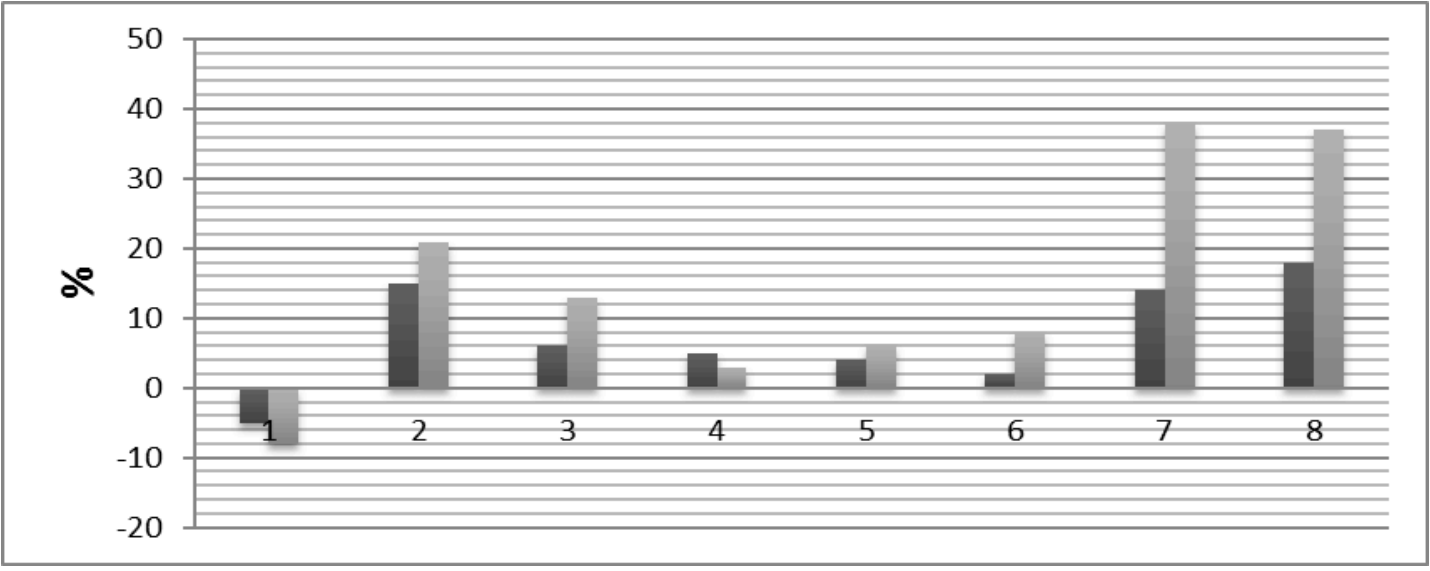

Characteristics

Fig. 5. Changes of pedaling bio-mechanical characteristics of elite cyclists in periods of fatigue's overcoming and evident fatigue during speed-power oriented trainings.

Legend: dark column - fatigue's overcoming, light column - evident fatigue. 1 - changes of pedaling velocity in respect to pre-set value; 2 -force impulse per cycle; 3 - effectiveness of efforts. Changes of efforts' kinematic characteristics; 4 - moment of start; 5 - moment of finish; 6 - moment of maximum; 7 - period of efforts' application; 8 - integrated bio-electrical activity of muscles per cycle. In diagram distinctions in respect to period of "stable workability" are depicted.

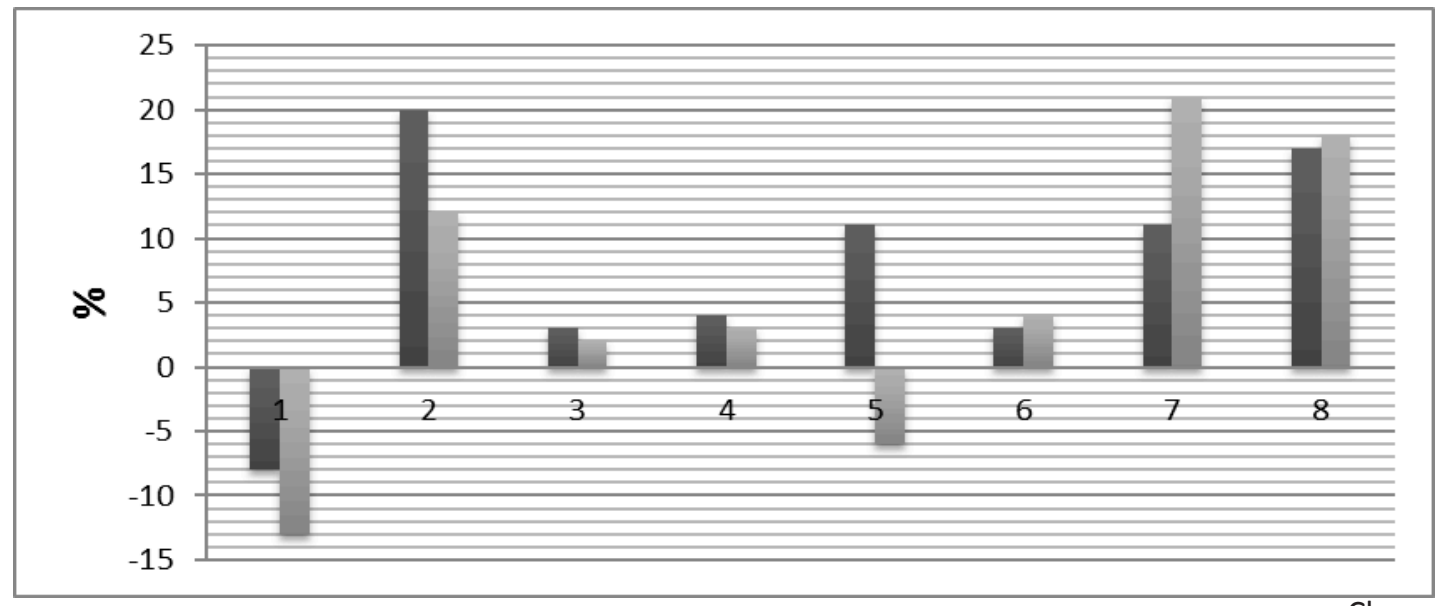

Characteristics

Fig. 6. Changes of pedaling bio-mechanical characteristics of elite cyclists in periods of fatigue's overcoming and evident fatigue during trainings of anaerobic orientation.

Legend: see fig. 5 .

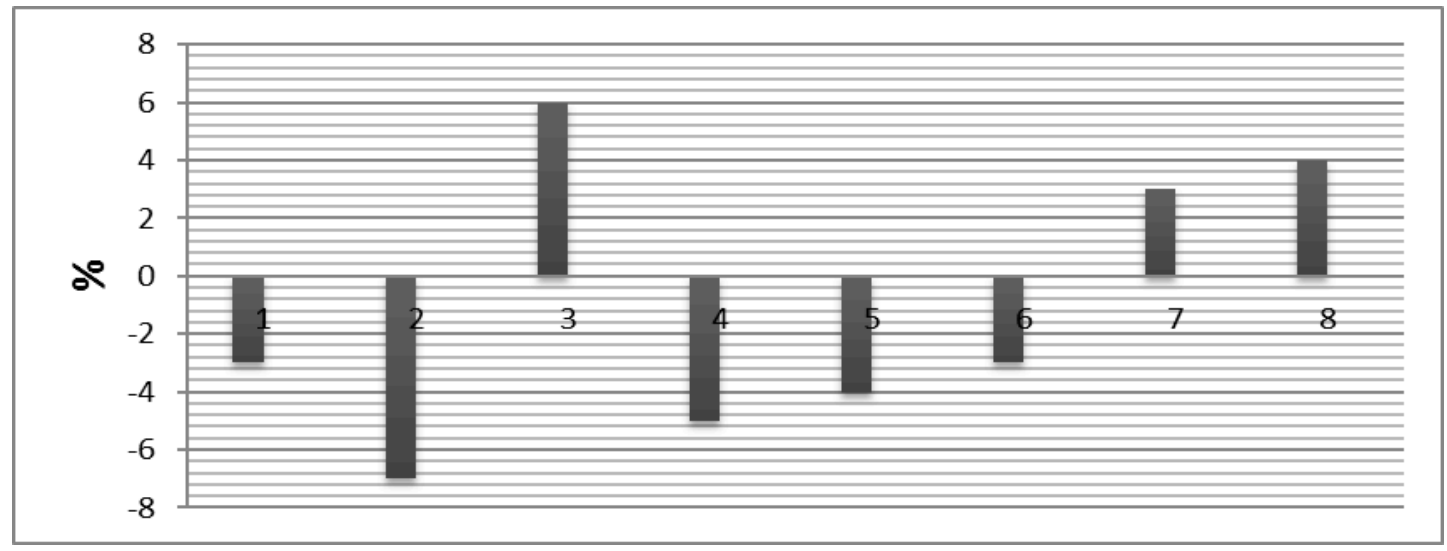

Characteristics

Fig. 7. Changes of bio-mechanical characteristics of elite cyclists in periods of fatigue's overcoming and evident fatigue at trainings of aerobic orientation.

Legend: see fig. 5 . 
connection one of the tasks of our research was study of movements' structure in period of evident fatigue. This period is characterized by reduction of pedaling velocity, which irreversibly reduced lower than admissible level in spite of all sportsmen's will to keep it.

In our study we found that in period of evident fatigue bio-dynamic picture of cyclists' efforts changes. Variability of movements' kinematic characteristics confidently increases as well as integrated bio-electric activity of the tested muscles, while efficiency of cyclists' work reduces (see figs. 5-7). Synchronized rhythm of motor units' activity oftener is replaced by poly-phase bio-potentials.

\section{Discussion}

The work against the background of fatigue's overcoming at trainings of different orientation rather positively influences on sportsmen movements' structure. Such work naturally stimulates compensatory reactions [3]. The most characteristic is increase of muscles' functioning tension. It expressed in involvement of additional motor units at trainings of speed-power and anaerobic orientation; in increase frequency of motor neurons' impulses. It also expressed in activity redistribution at level of separate muscles and muscle groups at trainings for endurance to aerobic work. In period of fatigue's overcoming there happens "correction" of external characteristics of movements and significance of the so-called "lagging behind" elements of pedaling structure increases. In such cases it is very important to increase activity of cyclists' resulting efforts' usage. The mentioned by us changes in pedaling structure in period of evident fatigue witness about weakening of muscles' contraction function and emersion of discoordination in nervous centers' functioning [11, 21, 25, 28]. In opinion of some authors $[1,6,14,17]$, increase of bio-potential oscillations' amplitude and reduction of frequency characteristics of electric myogram (like in our researches) witness about involvement of additional motor units in active state [7, 14, 29].

The received by us data permit to assume that there

\section{References}

1. Ajiboye AB, Weir RF. Muscle synergies as a predictive framework for the EMG patterns of new hand postures. Journal of Neuralogy and Engineering, 2009;6:036004.

2. Ambrosini E, Ferrante S, Ferrigno G, Molteni F, Pedrocchi A. Cycling induced by electrical stimulation improves muscle activation and symmetry during pedaling in hemiparetic patients. IEEE Transaction on Neural Systems \& Rehabilitation Engineering, 2012;20:320-330.

3. Bernstein N. The Coordination and Regulation of Movement. Oxford: Pergamon, 1967.

4. Boning D, Gonen Y, Maassen N. Relationship between workload, pedal frequency, and physical fitness. International Journal of Sports Medicine, 1984;5:92-97.

5. Castronovo AM, De Marchis C, Bibbo D, Conforto S, Schmid M, D’Alessio T. Neuromuscular adaptations during submaximal prolonged cycling. Conf. Proc. IEEE Medicine \& Engineering of Biology Society, 2012:3612-3615. are distinctions in mechanisms of muscular contractions strength gradation in period of fatigue's overcoming, when fulfilling work of different intensity [8, 15, 32]. With it, ability to involve additional motor units under maximal loads is a substantial reserve of sustaining muscular contraction magnitude [2, 27]. When working in optimal temp, the factor of muscular activity level (in period of fatigue's overcoming) is differentiation of motor units' excitation rhythm $[26,31]$.

High level of muscular activity's re-switching in conditions of different tiredness shall be regarded as coordination re-constructions in correlations of controlling centers. It permits to sustain resulting dynamic component of work $[5,10]$.

The received data can be used as diagnostic model of fatigue's influence on cyclists' movements' structure in different periods of their muscular functioning. Besides, these data can be used as model of dynamic of such state progressing in differently oriented trainings. Such approach will facilitate increase of effectiveness of cyclists' motor perfection in training process.

\section{Conclusions}

1. In period of fatigue's overcoming dynamic shocks in character of applied efforts disappear and the picture of bio-dynamic components becomes smoother. With it relative use of efforts' horizontal components increases, while force impulse of vertical efforts remains practically unchanged.

2. In period of evident fatigue variability of movements' kinematic characteristics and integrated bioelectrical activity of the tested muscles increase, while efficiency of cyclists' work reduces.

3. Distinctions in cyclists' movements' structure in period of fatigue's overcoming witness about certain tendency to transition from "impulse" type of pedaling to "circular" type. It preconditioned increase of efforts' useful components' importance and effectiveness of their use.

\section{Conflict of interests}

The author declares that there is no conflict of interests.

6. Cheung V, d'Avella A, Bizzi E. Adjustment of motor patterns for load compensation via modulated activations of muscle synergies during natural behaviors. Journal of Neurophysiology, 2009;101:1235-1257.

7. Conforto S, D'Alessio T. Real time monitoring of muscular fatigue from dynamic surface myoelectric signals using a complex covariance approach. Medicine \& Engineering Physiology, 1999;21:225-234.

8. d'Avella A, Fernandez L, Portone A, Lacquaniti F. Modulation of phasic and tonic muscle synergies with reaching direction and speed. Journal of Neurophysiology, 2008;100:1433-1454.

9. Davis RR, Hull ML. Measurement of pedal loading in bicycling: II. Analysis and results. Journal of Biomechanics, 1981;14:857-872.

10.Dorel S, Drouet JM, Couturier A, Champoux Y. (2009). Changes of pedaling technique and muscle coordination during an exhaustive exercise. Medicine and Science in 
Sports and Exercise, 2009;41(6):1277-86.

11.Ericson MO. Mechanical muscular power output and work during ergometer cycling at different workloads and speeds. European Journal of Applied Physiology \& Occupational Physiology, 1988;57:382-387

12.Hodges PW, Bui BH. A comparison of computer-based methods for the determination of onset of muscle contraction using electromyography. Electroencephalography \& Clinical NeuroPhysiology, 1996;101:511-9.

13.Hug F, Dorel S. Electromyographic analysis of pedaling: a review. Journal of Electromyography and Kinesiology, 2009;19:182-198.

14.Hug F, Drouet JM, Champoux Y, Couturier A, Dorel S. Interindividual variability of electromyographic patterns and pedal force profiles in trained cyclists. European Journal of Applied Physiology, 2008;104:667-678.

15.Hug F, Turpin NA, Couturier A, Dorel S. Consistency of muscle synergies during pedaling across different mechanical constraints. Journal of Neurophysiology, 2011;106:91-103.

16.Hug F, Turpin NA, Guevel A, Dorel S. Is interindividual variability of EMG patterns in trained cyclists related to different muscle synergies? Journal of Applied Physiology, 2010;108:1727-1736.

17.Jorge M, Hull ML. Analysis of EMG measurements during pedaling. Journal of Biomechanics, 1986;19:683-94.

18.Lakomy HK. Measurement of work and power output using friction-loaded cycle ergometers. Ergonomics, 1986;29:509517.

19. Merletti R, Parker PA. Electromyography: Physiology, Engineering, \& Noninvasive Applications. Hoboken, NJ: Wiley, 2004.

20.Monogarov VD, Bratkovsky VK. Coordination motions of sportsmen in the period of the compensated fatigue during muscular work of cyclic character. Optimization of management by the process of perfection technical trade of sportsmen higher qualification, Kiev, 1979:36-43.

21.Mornieux G, Gollhofer A, Staperlfeldt B. Muscle coordination while pulling up during cycling. International Journal of Sports Medicine, 2010;31:843-846.
22.Mornieux G, Stapelfeldt B, Gollhofer A, Belli A. Effects of pedal type and pull-up action during cycling. International Journal of Sports Medicine, 2008;29:817-822.

23.Patterson RP, Moreno MI. Bicycle pedalling forces as a function of pedalling rate and power output. Medicine and Science in Sports and Exercise, 1990;22:512-516.

24.Patterson RP, Pearson JL, Fisher SV. The influence of flywheel weight and pedalling frequency on the biomechanics and physiological responses to bicycle exercise. Ergonomics, 1983;26:659-668

25.Person RS. Electromyography in researches of man. Moscow: Medicine; 1969.

26.Petrofsky JS. Frequency and amplitude analysis of the EMG during exercise on the bicycle ergometer. European Journal of Applied Physiology \& Occupational Pyhsiology, 1979;41:1-15.

27.Sanderson DJ. The influence of cadence and power output on the biomechanics of force application during steady-rate cycling in competitive and recreational cyclists. Journal of Sports Science. 1991;9:191-203.

28.Takaishi T, Yamamoto T, Ono T, Ito T, Moritani $\mathrm{T}$. Neuromuscular, metabolic, and kinetic adaptations for skilled pedaling performance in cyclists. Medicine and Science in Sports and Exercise, 1998;30:442-449.

29.Theurel J, Crepin M, Foissac M, Temprado JJ. Effects of different pedalling techniques on muscle fatigue and mechanical efficiency during prolonged cycling. Scandinavian Journal of Medicine and Science in Sports, 2011;22:714-721.

30.Ting LH, Kautz SA, Brown DA, Zajac FE. Phase reversal of biomechanical functions and muscle activity in backward pedaling. Journal of Neurophysiology, 1999;81:544-551.

31.Too D. Biomechanics of cycling and factors affecting performance. Sports Medicine, 1990;10:286-302

32.Zameziati C, Mornieuxm G, Rouffet D, Belli A. Relationship between the index of effectiveness indexes and the increase of muscular efficiency with cycling power. European Journal of Applied Physiology, 2006;96:274-281.

\section{Information about the author:}

Kolumbet A.N.; http://orcid.org/0000-0001-8775-4232; re_play@3g.ua; Kiev National University of Technology and Design; st. Nemirovich-Danchenko, 2, Kiev, 14013, Ukraine

Cite this article as: Kolumbet AN. Study of qualified cyclists movements' coordination structure in period of overcoming fatigue during differently oriented trainings. Physical education of students, 2017;2:72-77. doi:10.15561/20755279.2017.0204

The electronic version of this article is the complete one and can be found online at: http://www.sportedu.org.ua/index.php/PES/issue/archive

This is an Open Access article distributed under the terms of the Creative Commons Attribution License, which permits unrestricted use, distribution, and reproduction in any medium, provided the original work is properly cited (http://creativecommons.org/licenses/by/4.0/deed.en).

Received: 30.01 .2017

Accepted: 09.02.2017; Published: 04.04.2017 